\title{
SENTIR EN MOVIMIENTO: EMOCIONES DE MUJERES SALVADOREÑAS SOBRE LA VIDA COTIDIANA Y EL TRÁNSITO MIGRATORIO POR TAPACHULA, ESTADO DE CHIAPAS, MÉXICO ${ }^{1}$
}

\section{Macarena Williamson MODESTO²}

RESUMEN: A la luz de la teoría crítica feminista, este artículo explora el miedo, la rabia y el deseo envueltos en el tránsito migratorio de dos mujeres salvadoreńas en la ciudad de Tapachula, frontera sur de México con Guatemala. A través de un método etnográfico se busca ahondar en la producción de subjetividades en contextos de movilidad humana, poniendo el foco en los contextos de interacción social relacionadas con la transitoriedad de estas mujeres centroamericanas por esta ciudad fronteriza. Ambas migrantes residieron en esta ciudad durante más de cuatro meses hasta que lograron regularizar su situación migratoria en México para seguir camino a Estados Unidos. Se propone que el miedo, la rabia y el deseo al mismo tiempo que atravesadas por lógicas de desigualdad, emergen como fuerzas transformadoras para afrontar las violencias y vulnerabilidades del tránsito migratorio por la frontera sur.

PALABRAS CLAVES: tránsito; mujeres salvadoreñas; emociones; afectos; frontera sur.

\footnotetext{
1 Este artículo se basa en los hallazgos de la tesis de maestría en Antropología Social, línea de especialización género, violencias, sexualidades y migraciones del Centro de Investigaciones y Estudios Superiores en Antropología Social (CIESAS), Ciudad de México, titulada "Sentir en movimiento: emociones de mujeres centroamericanas en tránsito por Tapachula, estado de Chiapas" (2015-2017). Investigación financiada por el Consejo Nacional de Ciencia y Tecnología (CONACyT) y el Consejo Latinoamericano de Ciencias Sociales (CLACSO).

2 Centro de Investigaciones y Estudios Superiores en Antropología Social (CIESAS), Ciudad de México - Mexico. Mestre em Antropología Social, linha de especialização violências, gênero, sexualidades e migrações. Universidade Estadual de Campinas, Campinas - SP - Brasil. Doutoranda do Programa em Ciências Sociais, Estudos de gênero. ORCID: https://orcid.org/0000-0003-4194-3091.macawilliamson@gmail.com.
} 


\title{
FEELING ON MOVIMENT: EMOTIONS OF SALVADORAN WOMEN ABOUT EVERYDAY LIFE AND MIGRATORY TRANSIT THROUGH TAPACHULA, STATE OF CHIAPAS, MEXICO
}

\begin{abstract}
Through contributions of feminist critical theory this article explores: fear, anger and desire involved in the migratory transit of two Salvadorian women in the city of Tapachula, Mexico's southern border with Guatemala. Through an ethnographic method, this paper seeks to delve into the production of subjectivities in contexts of human mobility, focusing on the contexts of social interaction related to the transit of these Salvadorian women in this border city. Both migrants resided in this city for more than four months, until they managed to regularize their migration status in Mexico to continue their journey to Unites States. It is proposed that fear, anger and desire, although crossed by logics of inequality, also emerge as transforming forces to face the violence and vulnerabilities of migratory transit through the southern border of Mexico and Guatemala.
\end{abstract}

KEYWORDS: transit; salvadorian women; emotions; southern border.

\section{Introducción}

"Y ahora estar aquí sin nadie, sin nadie. Una hace un recuento y hace un tiempito estaba bien tenía mi casa, estaban mis hijos bien, no estaban sufriendo y ahora nada, otra vez. Es como volver a comenzar" (Mayra, 18 de octubre de 2016).

"Me dio un abrazo, pero fuerte, fuerte. Mamacita se me cuida no quiero que vayas a andar llorando y mucho menos, ya que muy pronto nos vamos a ver me dijo. Yo tengo la certeza de que muy pronto nos vamos a ver y pues si me dan la tarjeta mańana o si me la dan el viernes, yo me voy aproximadamente el viernes de la otra semana" (María José, 324 de noviembre de 2016).

Como una ruptura profunda que traza un antes y un después, la movilidad forzada implica un cambio de vida drástico donde lo único claro es que no hay vuelta atrás. Las narrativas que abren este artículo se enmarcan en el tránsito migratorio de una mujer cisheterosexual y una mujer transgénero salvadoreñas por Tapachula en el sureste mexicano, región fronteriza del estado de Chiapas 
con Guatemala. Parrini y Flores (2018) sugieren que la frontera sur se configura como un lugar de precariedades para la migración centroamericana, espacio que, por un lado, "condensa relaciones sociales y condiciones estructurales que intensifican la vulnerabilidad que experimentan los migrantes irregulares en sus viajes" (BASOK, 2015 apud PARRINI; FLORES, 2018, p.74). Pero, por otro lado, es un territorio en el que, "se entrecruzan las determinaciones materiales e históricas (del espacio) con las experiencias individuales y singulares (del lugar)" (PARRINI; FLORES, 2018, p. 74). Esta propuesta se inclina por explorar cómo las mujeres centroamericanas desde sus subjetividades ${ }^{3}$ afrontan las dinámicas de exclusión social durante la transitoriedad en Tapachula, iluminando las posibilidades de agencia en sus afectos y emociones ${ }^{4}$. Este trabajo pretende aportar una mirada diacrónica a las subjetividades del tránsito migratorio para explorar algunas experiencias ${ }^{5}$ emocionales y afectivas vividas por dos mujeres salvadoreñas en tránsito por Tapachula, mientras esperaban ser reconocidas como personas refugiadas. Se ahondará en la dimensión emocional del tránsito migratorio en la frontera sur para comprender cómo este proceso, atravesado por violencias y solidaridades produce subjetividades tanto en las mujeres migrantes como en los territorios por donde transitan.

A través de un análisis centrado en el contexto de interacción que movilizaron el miedo, la rabia y el deseo en Mayra y María José, se explorarán los sentidos que estas interlocutoras atribuyeron a esas experiencias emocionales

\footnotetext{
3 La construcción de subjetividades en contextos de desigualdad, es una de las grandes preocupaciones analíticas de distintas disciplinas de las ciencias sociales y humanas. En esta propuesta, el recorte teórico será a través el pensamiento de Avtar Brah (2011), para quien el mundo interno de los sujetos no se explica mecánicamente como resultado de los marcadores de diferencia los sitúan, sino como un proceso relacional, constante, no lineal y contradictorio en que la que están en juego las localización social e histórica y los elementos emocionales, corporales y psíquicos de los sujetos.

4 La pandemia del virus Covid19 es un parteaguas en el proceso globalizador. Este contexto de urgencia sanitaria a multiescala, ha implicado en términos generales la agudización del sistema de control de fronteras con la justificación de detener la propagación del virus. Globalmente, los gobiernos vienen adoptando medidas que restringen la movilidad tales como el aumento de las deportaciones, expulsiones y restricciones de ingreso y obtención de documentación para la regulación migratoria de las y los migrantes. La pandemia de Covid19 está empujando a nuevos regímenes de movilidad e inmovilidad que afectan las subjetividades y las condiciones de vida de quienes están en desplazamiento.

5 Para Avtar Brah (2011, p.145) la experiencia "es el lugar de formación del sujeto". Es una práctica de sentido simbólico y narrativo "que es la condición principal para la constitución de lo que llamamos «realidad»" (BRAH, 2011, p. 144). Nuestras diferencias -organizadas en relaciones históricas y situadas de poder- van encausando el campo de las experiencias. Para la autora, es crucial el vínculo entre cuerpo, frontera y geopolítica, en la medida en que las diferencias (expresadas en la vivencia del cuerpo, en el género, la clase social, la raza, la pertenencia étnica o situación migratoria) van modulando la posición social de los sujetos y con ello, guiando sus experiencias en diferentes espacios geopolíticos. Esto último es central para aproximarse a las experiencias de las mujeres centroamericanas durante sus trayectorias migratorias las cuales transmutan según los distintos momentos del desplazamiento. Aquí seguimos el rastro de algunas experiencias emocionales durante el tránsito migratorio de dos mujeres centroamericanas ad portas de la elección de Donald Trump.
} 
durante su tránsito migratorio por Tapachula. Esta propuesta comienza con algunos apuntes sobre vulnerabilidad, afectos y agencias teniendo como foco a las migrantes centroamericanas en la frontera sur de México. Prosigue con algunas claves sobre el éxodo forzado centroamericano a Tapachula, territorio de movilidades. Luego se presenta el abordaje teórico-metodológico que guía esta investigación, para continuar con los principales hallazgos etnográficos contenidos en las experiencias emocionales de Mayra y María José sobre el miedo, la rabia y el deseo, concluyendo con algunas reflexiones finales y posibles líneas de investigación para extender el campo de conocimiento de los afectos en contextos de movilidad latinoamericana.

\section{Llegar a la frontera antes que Donald Trump: vulnerabilidad, afectos y agencias de las migrantes centroamericanas.}

Con frecuencia, la producción discursiva accionada por los agentes humanitarios tiende a esencializar el cruce entre vulnerabilidad ${ }^{6}$ y movilidades, donde la categoría de vulnerabilidad es automáticamente equivalente a víctima. El problema de esta asociación inmediata, es que traza a un sujeto migrante ahistórico, facultado únicamente para relatar los sufrimientos y las violencias de la migración forzada omitiendo la riqueza y complejidad de otros sentidos inscritos en las narrativas de las movilidades, y que les confiere a los sujetos la posibilidad de pensarse a sí mismos en tiempo y espacio. Así, las formas de subjetivación no viven sólo dentro de los sujetos ni están suspendidas en el aire. Los afectos, emociones, subjetividades son vividas desde el cuerpo y están situadas en un tiempo, espacio, territorio ${ }^{7}$. En este sentido, las narrativas que

\footnotetext{
6 Judith Butler (2010) introduce los cruces entre cuerpo, vulnerabilidad y violencias. Para la autora, nuestra corporalidad nos hace inherentemente vulnerables ante el mundo exterior. Esto significa que el cuerpo como un espacio/territorio en el que se inscriben significados sociales, somos un cuerpo "que sufre, se alegra y responde a la exterioridad del mundo, una exterioridad que define su disposición, pasividad y actividad" (BUTLER, 2010, p. 58). Si bien nuestra única existencia implicaría que somos inherentemente vulnerables, el diálogo permanente de Butler con las dinámicas múltiples del poder le permite relacionar la exposición de ciertas corporalidades/existencias a la violencia, incitándonos a develar "los "marcos" que operan para diferenciar las vidas que podemos aprehender, de las que no podemos aprehender" (BUTLER, 2010, p.16). Esta idea me permite sostener que la exposición de ciertos cuerpos frente a diferentes violencias, se debe a los condicionamientos que imponen los marcadores de diferencia social sobre los sujetos.

7 Aludo a territorio porque parece una categoría más pertinente para explorar los diferentes circuitos y movilidades inscritas en las fronteras, vistas como entornos sociales, culturales, económicos, políticos y paisajísticos vinculantes de los saberes entre las comunidades de origen y los lugares de tránsito o residencia de las personas en movimiento. Este carácter polisémico de la frontera es abordado en profundidad por Sandro Mezzadra y Brett (2017) para quien estos territorios encarnan "múltiples componentes -legales, culturales, sociales y económicos- (...) la institución de la frontera tiende a desgarrarse de la línea magnética que corresponde a la línea de separación geopolítica entre Estados-nación" (MEZZADRA; BRETT, 2017, p. 21). Así la frontera suroccidental de México vista como un
} 
abren este artículo, indican que en la experiencia de transitoriedad las nociones sobre el pasado y la imaginación sobre el futuro son necesarias para seguir avanzando y para que los sujetos en movilidad no se queden atrapados en la transitoriedad.

En noviembre de 2016, la elección a la presidencia de Donald Trump en Estados Unidos ${ }^{8}$ agudizó algunos repertorios emocionales ya recurrentes en las narrativas de las mujeres migrantes en tránsito por el sureste mexicano, tales como la ansiedad, la preocupación, el estrés, entre otras ${ }^{9}$. Estas subjetividades envueltas en los procesos de movilidad influyen significativamente en la planificación del viaje y la ponderación de decisiones en la trayectoria migratoria. A las preocupaciones cotidianas por subsistir, a fines del año 2016 se sumaba la presión por obtener los documentos de legal estancia y llegar a la frontera de México con Estados Unidos antes que se extremaran las políticas restrictivas y de securitización de ambos estados. Este es el telón de fondo en el que ocurre el tránsito migratorio de Mayra y María José.

Durante el año 2016, los flujos centroamericanos a la frontera sur de México cristalizaban un éxodo forzado producto de una serie de violencias. Siguiendo a Amarela Varela Huerta (2017) las razones que empujan a las mujeres de Honduras, El Salvador y Guatemala a huir de sus lugares de origen es la conjugación de la violencia de mercado -entendida como las dinámicas de pobreza y desigualdad producto del extractivismo económico y el histórico intervencionismo de Estados Unidos en la región centroamericana-, la violencia estatal - donde el Estado reproduce políticas de control orientadas a categorizar las

territorio de movilidades, ilumina su carácter dinámico y transnacional superando los abordajes que la interpretan únicamente como un dispositivo geopolítico constitutivo de un Estado-nación.

8 La postura antiinmigrante frente a la política internacional fue una de las apuestas más potentes de Donald Trump durante el periodo de campaña que presidió su elección a principios de noviembre de 2016. Este hito es fundamental no sólo por el peso de Estados Unidos en las estrategias tecnocráticas y geopolíticas de las políticas migratorias, las cuales marcan la pauta en relación a la gestión de las movilidades a nivel global, pero también porque anuncian la impronta del neoconservadurismo y los fundamentalismos religiosos como centrales en los procesos de gobernabilidad democrática. El posicionamiento antiinmigrante, directamente relacionado con el triunfo del proyecto político de Donald Trump vino a tensionar el complejo encadenamiento entre capitalismo, colonialismo y patriarcado, que según Gandásegui y Preciado (2017, p. 29) produjo "la dominación de un bloque hegemónico, nacionalista, populista, conservador y racista".

9 Durante el trabajo de campo y acompañamiento cotidiano a Mayra y María José algunos se expresaron cambios corporales relacionados a estos repertorios negativos, como variación de peso, dolores de cabeza recurrentes, brotes en la cara, agudización de cuadros preexistentes, entre otros. Estas transformaciones en el cuerpo estaban directamente relacionadas a sus condiciones de vida en el tránsito. En general no comían mucho, dormían poco (además al menos dos días de la semana estaban destinados para los trámites de regularización-el funcionamiento burocrático del Instituto Nacional de Migraciones empujaba a las personas en movilidad a hacer filas para atención desde las 4:00 am) además, las altas temperaturas de Tapachula contribuían a la sensación de cansancio y fatiga. 
vidas vivibles, de las desechables- y la violencia feminicida ${ }^{10}$-que imprime en el cuerpo de las mujeres mensajes de disputa del poder entre pares-. Pero esta "trinidad perversa" en palabras de la autora, no se acaba con la huida. A través de las narrativas de Mayra y María José veremos cómo las trayectorias migratorias de las mujeres migrantes centroamericanas, se proyecta como un continuum de violencias (SCHEPER-HUGHES; BOURGOIS, 2004, p. 1) que pone en riesgo sus vidas en diferentes momentos de la trayectoria migratoria.

Gran parte de los estudios interdisciplinarios de la migración centroamericana en la frontera suroccidental abordan las violencias, vulnerabilidades y agencias de las mujeres migrantes centroamericanas en territorio mexicano. Por nombrar sólo algunas, destacan los trabajos de las investigadoras Carmen Fernández (2019), Martha Rojas (2017), Hiroko Asakura (2016, 2019), Amarela Varela Huerta (2017), Ailse Winton (2016) entre otras autoras de diferentes disciplinas de las ciencias sociales que se han volcado a explorar los múltiples ángulos de las movilidades en la frontera sur. Pero, ¿por qué abordar las emociones y afectos de las mujeres centroamericanas como formas agencia frente a las precariedades del tránsito migratorio? Las emociones y los afectos, entendidos como "fuerzas en constante formación" (MORAÑA, 2012, p. 324) son un camino de exploración a las múltiples formas de agencia implicadas en las subjetividades migrantes en los diferentes territorios. Poner el foco en la interpretación corporal, emocional y afectiva del tránsito migratorio de las mujeres migrantes nos permite avanzar en un análisis donde la frontera y el tránsito son vistos de modo mucho más complejos que su relativización como división geopolítica ${ }^{11}$ (MEZZADRA; BRETT, 2017).

Así, los afectos y las emociones abordadas como potencias que acceden a lo simbólico y a lo imaginado, encarnan tanto la consolidación de los biopoderes como las estrategias de resistencia a estas lógicas del poder (MORANA, 2012). En este artículo, se exploran los procesos de subjetivación en situaciones

\footnotetext{
${ }^{10}$ Las feministas Jill Radford y Diana Russel en la obra "Femicide. The politics of woman killing" plantearon por primera vez el concepto de feminicide en inglés en el año 1992. Situada desde la experiencia de la violencia machista, los asesinatos y desapariciones de mujeres en Ciudad Juarez, Marcela Lagarde (2011), Patricia Ravelo (2017) y otras antropólogas mexicanas ampliaron la noción de feminicidio para referirse no sólo a los asesinatos con razón de género, sino a todas las conductas violentas que pueden conducir a la muerte trágica de las mujeres, en las que también es central la violencia estructural, institucional y simbólica del Estado. Estas autoras marcaron un precedente en la lucha contra el feminicidio en América Latina, impulsando en México la Ley General de Acceso a las Mujeres de una Vida Libre de Violencia en el año 2006.

${ }^{11}$ En esta propuesta la frontera es mucho más que un proceso de demarcación, es una categoría simbólica, social y cultural inscrita desde antes en los cuerpos de las personas en movilidad. El acento, el color de la piel, el género, la condición de clase y la situación migratoria entre otros marcadores de diferencia actúan como fronteras simbólicas, pero normativizadas que van condicionando las trayectorias migratorias de las personas en movimiento.
} 
de movilidad, conectando el sentir interno de quienes se desplazan con sus condiciones objetivas e históricas de vida. En el marco del tránsito de las mujeres centroamericanas por la frontera sur de México, acceder a estas narrativas ilumina la centralidad de la agencia en las subjetividades para afrontar los riesgos de la movilidad forzada, tensionando la verticalidad del poder inscrita en la producción discursiva de la vulnerabilidad accionada por el aparato humanitario. Los relatos de vida de las mujeres trabajadoras, migrantes, racializadas, transgénero, interpelan los modos en que se acciona la categoría de víctima y nos lleva a transitar a enfoques que documentan las agencias de las mujeres migrantes y sus posibilidades en el mundo. Esta potencialidad es la que estoy buscando en la dimensión emocional de la transitoriedad en Tapachula, con el propósito de contribuir a extender los estudios de género, sexualidades y subjetividades en las movilidades que atraviesan la frontera sur de México.

\section{Claves sobre el éxodo forzado salvadoreño a Tapachula, territorio de movilidades}

La historia reciente de El Salvador está atravesada por diferentes escalas de violencia -política, estructural, simbólica, cotidiana ${ }^{12}$-, dejando huellas en la vida privada y pública de la sociedad salvadoreńa. Desde principios del $2000 \mathrm{el}$ manodurismo vino a agudizar el escenario de violencia a través de persecuciones y asesinatos contra pandilleros en barrios y comunidades de El Salvador. Así se va configurando un escenario de muerte entre las pandillas, el Estado y la sociedad civil, cuyo manto de fondo es la desigualdad social, la transnacionalización de

\footnotetext{
${ }^{12}$ La guerra civil de este país trajo dramáticas consecuencias para la sociedad civil con más de 30 mil fusilamientos -según el Informe de la Comisión para la Verdad de El Salvador (1993)-, desplazamiento forzado interno y externo, y varias masacres a campesinos. A principios de los años ochenta el aumento de la violencia y la persecución política agudizó la pobreza del país fomentando los flujos migratorios a Estados Unidos y Canadá. Una década más tarde -después de las firmas de paz- se produjo una desaceleración de los movimientos migratorios y un aumento del retorno de los emigrados de la guerra. No obstante, persistieron las precarias condiciones económicas en El Salvador. Ferrandiz y Feixa (2004) sintetizan algunas características de la violencia política, estructural, simbólica y cotidiana, aportando claves para comprender la yuxtaposición de estas modalidades de violencias en las trayectorias migratorias de las mujeres centroamericanas. Por violencia política los autores entienden las formas de agresión física y terror administradas por las autoridades oficiales y por aquellos que se les oponen. Aquí destacan la represión militar, tortura policial y resistencia armada en nombre de una ideología, movimiento o estado político. En relación a la violencia estructural, los autores la identifican como la organización económico-político de la sociedad que impone condiciones de dolor físico y/o emocional a la soberanía. La violencia simbólica -inicialmente definida por Bourdieu- constituyen todas esas humillaciones internalizadas que cristalizan formas de legitimación de la desigualdad. Aquí destacan las jerarquías que devienen marcadores sociales de diferencia como el género, la raza o étnica hasta las expresiones internas del poder de clases. Finalmente, la violencia cotidiana dice relación con la experiencia individual que normaliza las brutalidades en la comunidad y crea un sentido común o ethos de la violencia" (FERRANDIZ; FEIXA, 2004, p.162-163). En la frontera sur estas formas de violencia se funden en los diferentes momentos de la de la trayectoria migratoria de las mujeres centroamericanas en tránsito por México.
} 
los recursos naturales, el intervencionismo norteamericano y la misoginia como herramienta de poder tanto de las maras ${ }^{13}$ como de las fuerzas policiales. Esta migración forzada se funde con el control fronterizo de México cuyas políticas migratorias se insertan en la lógica de control de fronteras global conocido como border regime, "la intensificación de todo tipo de muros y vallas, de tecnología de identificación y control, que se despliegan a través de múltiples fronteras y filtros, donde con demasiada regularidad, como dice Agier en sus estudios etnográficos, el refugiado termina por ser un indocumentado" (CASTRO, 2019, p. 21). Así, la movilidad forzada centroamericana es acorralada y fuertemente criminalizada por las políticas migratorias restrictivas operando a lo largo de toda la frontera sur ${ }^{14}$. Esta forma de gestión de las movilidades a nivel global ha pretendido contener los flujos migratorios centroamericanos en territorio mexicano para impedir su llegada a la frontera norte con Estados Unidos ${ }^{15}$.

Sin embargo, Sherry B. Ortner (1995) sugiere que el poder no es una fuerza vertical que se mueve unilateralmente de arriba a abajo, desde la dominación a la sumisión. Las lógicas del poder son dinámicas, no una expresión binaria pendular, al respecto Saba Mahmood (2019) retoma a Foucault para proponer que el

\footnotetext{
${ }_{13}^{13}$ Las maras o pandillas como serán entendidas aquí, nacieron producto de las movilidades generadas por la guerra civil en El Salvador. Se conformaron en Estados Unidos durante la década de los 80' por las migraciones provocadas por la violencia de la guerra civil en este país -que cesó en 1992 con de los Acuerdos de Paz de Chapultepec entre el gobierno y el frente Farabundo Martí para la Liberación Nacional (FMLN)-. Las maras surgieron como producto de un proceso de exclusión de las comunidades centroamericanas en Estados Unidos empujando a la conformación de pandillas centroamericanas para defenderse y diferenciarse de bandas asiáticas, blancas, mexicanas, puertorriqueñas y negras. Según Ángeles (2004), mara es como se le dice a un grupo de niños o jóvenes que sostienen una relación de amistad en El Salvador y Honduras (ÁNGELES, 2004), cuando se refieren a un grupo también se le denomina "clica", "crew", entre otras. Y trucha, categoría émica, para referirse estar alerta, atento. Los números 13 y 18 se deben a las calles donde se formaron las maras en la ciudad de Los Ángeles, Estados Unidos, además estos números señalan la adherencia a alguna de estas bandas, vinculadas (antiguamente) con la práctica del tatuaje como una forma de pertenencia a estos grupos en el cuerpo. Para controlar la expansión de las pandillas a principio de los años 2000, el gobierno salvadoreño lanzó el Programa Antimaras Acero extendiéndose hasta frontera sur de México, implementándose desde el año 2003 al 2004. En esa misma época en Honduras y El Salvador se legisló para que la pertenencia a alguna pandilla fuera un delito. No obstante, estas medidas no detuvieron la expansión del crimen organizado.

${ }^{14}$ Según Yerko Castro (2019) el border regime, genera grandes utilidades económicas a costa de mantener los centros de detención, refugios o albergues, prolongando la incertidumbre de la transitoriedad de las comunidades migrantes, quienes resultan presas de su movilidad.

${ }_{15}$ Desde el año 2014, durante la administración de Enrique Peña Nieto entró en vigencia el Programa Integral Frontera Sur, política binacional que según un informe publicado en 2017 por la unidad de investigación del Congreso estadounidense, este país proporciona casi 100 millones de dólares en financiamiento, equipamiento y capacitación a los funcionarios del Instituto Nacional de Migraciones de México. Este programa promueve la deportación y pone obstáculos al proceso de obtención de asilo y refugio. La criminalización de la movilidad humana se agravó después de la noche del 8 de noviembre de 2016, cuando Donald Trump resultó electo presidente de Estados Unidos. Al estrés del engorroso proceso de regularización migratoria, se sumó la ansiedad de las y los migrantes centroamericanos, haitianos, pakistaníes y africanos (en su mayoría provenientes de Angola) en tránsito por Tapachula por obtener con urgencia documentos de legal estancia para seguir su camino a Estados Unidos.
} 
poder es "una relación de fuerzas estratégicas que permea la vida, deseos, objetos, relaciones y discursos" (MAHMOOD, 2019, p. 149). Esto último queda claro en los espacios agencia de las y los migrantes centroamericanos, los cuales se han amplificado y masificado con fuerza años incluso después de la elección de Donald Trump. Ejemplo de ello son las caravanas centroamericanas de migrantes que en los años 2017, 2018 y 2019 las cuales convocaron masivamente a miles de personas salvadoreńas, guatemaltecas y hondureñas a salir de sus lugares de origen para cruzar México y seguir hasta la frontera norte con Estados Unidos. Esta estrategia de organización de los migrantes centroamericanos, ocurre en medio del neoconservadurismo y en una de las ofensivas más fuertes contra la movilidad humana, encarnada en la postura antiinmigrante de Donald Trump ${ }^{16}$. Desde el año 2016, hay algunas transformaciones en la consolidación de ciertos colectivos migrantes, entre ellos, de las diversidades sexuales o LGBTI+. En estas caravanas ${ }^{17}$ ya existían migrantes centroamericanos LGBTI+ organizados que comenzaron a articularse para afrontar las necesidades y violencias específicas de las comunidades disidentes sexuales en tránsito por México. Ana María Maurer (2019), sugiere que la conformación de los contingentes LGTBI+ en las caravanas centroamericanas son en sí mismas una forma de movilidad caracterizada por sus prácticas de alojamiento y "autoprotección” migrantes. Durante la caravana el contingente LGTBI+ logró articular diferentes prácticas que les permitieron recibir apoyo, prescindiendo de las intervenciones de organizaciones humanitarias (MAURER, 2019).

De esta manera, las caravanas en tránsito por México evidencian, por un lado, la situación de vulnerabilidad de las comunidades excluidas a ejercer sus derechos en los países del Triángulo Norte de Centroamérica, pero, por otro lado, imprimen nuevos regímenes de visibilidad a las luchas migrantes a nivel global. En este sentido, el éxodo centroamericano encarnado en las caravanas se conformó como una estrategia de sobrevivencia que, atravesada por dolor y

\footnotetext{
${ }^{16}$ Desde su existencia, las caravanas han puesto en jaque el aparato securitario, las políticas migratorias restrictivas y, en definitiva, la gobernabilidad migratoria entendidas como tecnologías de control y disciplinamiento de las movilidades a nivel global. Pero también son importantes las controversias que despiertan estas caravanas entre los actores envueltos en la razón humanitaria de la migración centroamericana. Las caravanas no son espacios políticamente neutrales, ocurren disputas de poder entre las narrativas de las organizaciones no gubernamentales, los agentes del aparato humanitario y las formas de organización autónomas de las y los migrantes.

${ }^{17}$ En la historia reciente de los flujos centroamericanos en la frontera sur de México con Guatemala, ha habido principalmente dos caravanas que se han hecho visibles. Una de ellas es la caravana de madres de migrantes desaparecidos, procesión que parte desde Honduras y atraviesa todo México. Desde el año 2012, ésta convoca a madres de personas centroamericanas desaparecidas en tránsito hacia Estados Unidos de las cuales no hay rastro desde su partida. Las otras, son las sucesivas caravanas de migrantes que comenzaron con dos oleadas el año 2017 y una oleada el 2018. Es importante situar históricamente la emergencia de las caravanas, pues están directamente relacionadas con la política migratoria internacional de México y Estados Unidos, y el régimen migratorio global.
} 
sufrimiento demostró ser una forma de ofensiva a la política antiinmigrante de México y Estados Unidos. Las caravanas deben ser vistas desde sus precedentes históricos, en este contexto se insertan las narrativas del tránsito de Mayra y María José las que cristalizan la conquista por la movilidad como un derecho humano y la búsqueda de la dignidad.

\section{Abordaje teórico-metodológico: emociones, afectos y género en la antropología}

A mediados de los años 1970, el giro afectivo en la antropología, impulsado por antropólogas y sociológicas feministas, principalmente desde el pensamiento de Michelle Rosaldo (1984), ampliaron los marcos de comprensión de las emociones y los afectos como construcciones histórico-culturales que guían, norman y conducen la acción de los sujetos. El estudio de las emociones en la antropología no sólo removió los marcos epistemológicos y teóricos con los cuáles se buscaba explorar las subjetividades del "otro", sino que también implicó una verdadera ruptura frente al positivismo en las ciencias sociales y humanas. Desde los años setenta del siglo pasado en adelante, los enfoques de antropología y sociología de las emociones han seguido expandiéndose, y hoy en día es un amplio campo de producción de conocimiento interdisciplinario con múltiples vertientes teóricas, algunas inclinadas por la biopolítica, otros enfoques estructuralista, psicoanalista, psicosocial, entre otros.

La influencia del pensamiento feminista ha sido sustancial para dilucidar el orden de género y otras categorías de articulación en las normas emocionales. La teoría crítica feminista ha puesto en tensión el giro afectivo poniendo en el centro las lógicas del poder. El interés de las teóricas críticas feministas y queer sobre las emociones comienza por concebir la práctica feminista como un ejercicio político "impregnado de sentimientos, pasiones y emociones" (PEDWELL; WHITEHEAD, 2012, p. 116), reconociendo los vínculos críticos entre los afectos y las relaciones de poder de género, sexo, raza y clase social.

En esta propuesta, ubico en el centro a las emociones y los afectos como categoría de análisis para acceder a la experiencia de la transitoriedad en la frontera sur de México. Siguiendo a Moraña, "La producción y transmisión de afecto conecta las distintas instancias de la vida, la relación entre sujeto y acción, entre cuerpo y no cuerpo, entre evento y sujeto" (MORAÑA, 2012, p. 318). Acceder a las experiencias emocionales de las mujeres migrantes, cristaliza cómo se producen subjetividades en contextos de movilidad. Las emociones y los afectos vistas como fuerzas que guían la acción social, son también construcciones 
históricas y contextuales nacidas desde interacciones sociales atravesadas por disputas de poder. Olivia López (2011), sostiene que las emociones conectan las esferas micro y macrosocial -refiriendo a un sentir interno, pero también a las condiciones objetivas de vida de los sujetos- en las que operan las categorías de articulación,

Las emociones como recurso analítico permiten el estudio microsocial y macrosocial en la medida que entendemos que las emociones son producto de lo social, y lo social definitivamente afecta la variación emocional. La variación en la expresión emocional está asociada a la pertenencia social (género, edad, etnia, clase social), la cual promueve y permite ciertos rangos en el uso del cuerpo y sus expresiones en la interacción social (LÓPEZ, 2011, p. 41).

Para operacionalizar el miedo, la rabia y el deseo abordé dos ejes de análisis, el contexto de la emoción y la experiencia. Según Marina Ariza, "Mientras el contexto proporciona el marco perceptual y cognitivo desde el cual quienes interactúan harán sus inferencias (Goffman, Op. Cit.; Joseph, Op.cit), la experiencia es la forma en que dicha interacción se actualiza (retiene) en la conciencia" (ARIZA, 2016, p. 294). En este ejercicio, intentaré recrear el contexto de interacción particular (ARIZA, 2016) que detonó las emociones del miedo, la rabia y el deseo. Aquí no sólo es importante la situación de interacción, sino su corporeización y los sentidos que adquieren para las interlocutoras.

Tanto la migración forzada como las políticas restrictivas enmarcan la experiencia migratoria de Mayra y María José. Como gran parte de las y los migrantes que llegan a la frontera sur, por obligación ambas debieron residir temporalmente en Tapachula hasta obtener el estatus de refugiadas ante la COMAR (Comisión Mexicana de Ayuda a los Refugiados) y el ACNUR (Alto Comisionado de las Naciones Unidas para los Refugiados). Sabían que es riesgoso ser migrantes indocumentadas en México; a las amenazas latentes de la deportación, se suma la exposición a secuestros, robos y violaciones durante la travesía a la frontera norte.

Mayra, mujer cisheterosexual de 33 años con cuatro hijos y su compañero, huyeron de San Rafael Cedros la misma noche de la amenaza de muerte por la mara salvatrucha. Junto a su familia cruzaron por Tecún Umán, Guatemala en septiembre de 2016. En marzo del 2017, volvió a ser amenazada por pandilleros de la misma banda en Tapachula por lo que debió huir nuevamente. En la actualidad, se encuentra en otro estado mexicano. Es 
recurrente que quienes migran forzosamente, vivan varios reasentamientos buscando protección y seguridad. María José es una joven transgénero de 28 años que huyó de su natal Santa Ana debido a la extorsión de las maras barrio 18. En agosto de 2016, junto a Lucero, una amiga transgénero, cruzaron en balsa por el río Suchiate desde Tecún Umán, Guatemala a Ciudad Hidalgo, México. María José sufrió uno de los primeros embates de la criminalización cuando estuvo detenida por 44 días por no tener documentos de legal estancia en el centro de detención para migrantes más grande de América Latina, la Estación Migratoria S. XXI. Esta verdadera cárcel para migrantes está dividida en secciones para hombres y mujeres, siendo María José reenviada a la sección de hombres vulnerándose su derecho a la identidad social y de género, yo la conocí después de que salió del centro de detención. Pasaron seis meses hasta que, en enero de 2017, María José logró cruzar a Estados Unidos por el paso Tijuana. No obstante, dado que no tenía documentos de legal estancia en este país y porque debía comprobar su solicitud de refugio por huir de la violencia, estuvo detenida durante seis meses en un centro de detención para personas migrantes en San Diego como ocurre centenares de migrantes criminalizados ${ }^{18}$.

Con Mayra y María José establecimos un vínculo estrecho que fue fundamental para acceder a sus experiencias emocionales durante el tránsito migratorio. Nos reuníamos en sus hogares provisorios o en un espacio que me facilitó los días miércoles el Centro de Derechos Humanos Fray Matías. Las acompañé a buena parte de sus trámites y quehaceres de la vida cotidiana. Las condiciones de precariedad económica y discriminación laboral en Tapachula empuja a las y los migrantes a depender de los vínculos con las instituciones y organizaciones. A su llegada se sostienen con la ayuda humanitaria de ACNUR, pero después de un mes deben generar diversas estrategias para resolver sus necesidades básicas de existencia.

\footnotetext{
${ }^{18} \mathrm{La}$ frontera suroccidental es un territorio poroso en el que conviven víctimas y victimarios. La migración forzada centroamericana adquiere un carácter difuso en la región de Soconusco, entre quienes llegan solicitando refugio por ser víctimas de la violencia de los grupos criminales, quienes buscan desvincularse de las pandillas -amenazados de muerte- o quienes participan de estos grupos criminales desde México. Esto demuestra que la violencia de la migración forzada no se acaba en sus países de origen y que el carácter transnacional de las pandillas hace que el miedo persista en el tránsito.
} 


\section{Miedo, rabia y deseo: emociones de la vida cotidiana de dos migrantes salvadoreñas en tránsito por Tapachula, Chiapas}

\section{El miedo en el tránsito}

Mayra de ojos cristalinos estaba sentada sobre las estructuras de concreto que delimitan las palmeras, flores y arbustos del Parque Hidalgo, uno de los principales puntos de reunión en Tapachula. Relató que habían llegado hace dos semanas a la ciudad y que junto a su familia estaban quedándose en el Hotel San Agustín (ubicado en el centro de la ciudad). A ese hospedaje llegaban las personas solicitantes de refugio que ACNUR financiaba como parte de la ayuda humanitaria que presta a los migrantes. En uno de los pasillos del hotel reconoció a unos pandilleros que eran de su lugar de origen. Junto a su familia decidieron no salir del cuarto en todo el día hasta la mañana siguiente, "yo vengo huyendo de ellos y ahora me los encuentro aquí". El reencuentro con el sujeto amenazante fue suficiente para despertar la memoria del miedo de nuevo, emoción que según Sara Ahmed implica una anticipación del sufrimiento (AHMED, 2015). En el siguiente extracto, Mayra explica por qué y cómo huyó de San Rafael Cedros, su lugar de origen. El tono emocional de su relato, atravesado por la amenaza de muerte de los pandilleros, demuestra que las subjetividades de la huida forzada, supone vivir una constelación de emociones. En la narrativa de Mayra, enojo, nervios, miedo. Y desde el momento de la amenaza que los llevó a huir, la búsqueda del sentido sobre lo que ocurrió:

"Me puse a comprar ropa usada y nueva y con eso empecé, después nos fuimos a vender juntos con el papá de ellos [de sus hijos] y así el negocio lo hicimos un poquito más grande, entonces sentía que en la vida todo se iba acomodando. Yo sentía como que ya iba a descansar, que mis hijos iban a estar bien. Pasamos tres años de lo más tranquilos. Cuando se empezó a sentir que estaban esos pandilleros. Ya después no podía entrar a las colonias. Carlos trabajaba en las motos y ahí empezaron a pedirle ride $^{19}$, le quitaban sus gorras y así. Cuando ya nos llegaron a pedir dinero yo me enojé mucho con él (con su pareja), era de los mismos nervios que me enojé. Si él no les hubiese dado dinero, ellos no hubiesen venido. Y en realidad de que iban a llegar, iban a llegar, pero al mismo tiempo ya ellos empezaron a quitar 300 dólares mensuales, Macarena, cualquiera puede

${ }^{19}$ Categoría emic de El Salvador para pedir un viaje en moto como medio de transporte. 
decir que no es nada, pero a nosotros ya no nos alcanzaba, ya no vendíamos. Querían 1000 dólares de un sopetón. Nos llegaron en la noche y le dijeron a él que buscaban el dinero, que lo iban a ir a recoger a las $8 \mathrm{de}$ la mañana, que si no, le iban a dar donde más le duele que iban a partir por mí y después con los niños. ¿cómo iba a tener 1000 dólares así? Mire, como que todo se me dio vuelta y bendito sea Dios, esa noche hubo una emboscada contra dos policías entonces esa misma noche nos fuimos y dejamos todito. Entonces no es lo mismo salir a pasear que salir huyendo" (conversación, Mayra 3 de octubre de 2016).

En el tránsito por la frontera sur, Mayra y su familia no están libres de sentir miedo, esta norma emocional empleada por las pandillas se extiende más allá las fronteras de su lugar de origen. Para Sara Ahmed (2015) el miedo es una emoción que alerta de un riesgo. Se enuncia desde un yo que quiere distanciarse de otro, trazando los límites de la alteridad. En el contexto de interacción de Mayra, reconocer a uno de los pandilleros de su lugar de origen en Tapachula implicó reavivar el miedo que le alertaba del sufrimiento. Aunque el pandillero no le hiciera nada, la memoria de la amenaza como una anticipación del sufrimiento, restringe su movilidad y se encarna como una experiencia intensa, que "constituye a los otros como temibles, en tanto amenazan con absorber el yo" (AHMED, 2015, p.107).

El 11 de septiembre de 2001 fue un hito clave en el fortalecimiento de una economía global del miedo (AHMED, 2015) con una producción discursiva orientada principalmente al terrorismo y la movilidad humana. En el marco de la migración indocumentada, Aquino (2015) explora el miedo desde la biopolítica para sostener que esta emoción es una "tecnología disciplinaria" que pretende dosificar el cuerpo migrante. Pero la autora pone énfasis en sus prácticas que les permite gestionar el miedo en su cotidianeidad.

Mapeando la configuración de las pandillas, Rosana Reguillo (2007) propone, que en el advenimiento del discurso del miedo social y la retórica de la seguridad, las pandillas han podido expandir su poder creando un sistema paralegal que les ha permitido configurarse no solo como un grupo translocal, sino también transnacional (REGUILLO, 2007). De esta manera, las y los migrantes en tránsito están envueltos en diferentes situaciones contextuales y discursivas relativas al miedo. Durante el tránsito migratorio Mayra y María José experimentaron el miedo desde al menos dos sentidos diferentes. Por un lado, el miedo accionado como dispositivo o tecnología de poder fomentada por los estados y las instituciones que permanentemente intentan regular y controlar la movi- 
lidad humana, -así el temor constante a ser presas e indocumentadas, cuando debían ser protegidas por ser migrantes forzadas-. Y el miedo transnacional a las pandillas, a esa convivencia latente con las amenazas incluso en el lugar donde se busca refugio. Estas distintas interacciones sociales en las que emerge el miedo tienen en común que "funcionan para restringir a ciertos cuerpos, a través del movimiento o la expansión de otro" (AHMED, 2015, p.115).

El miedo de Mayra en el hospedaje de acogida demuestra que migración forzada es un fenómeno transnacional y local. Esta experiencia no se acaba en el país de origen, sino que vuelve a encarnarse todas las veces que implique un reencuentro con el sujeto amenazante. Después de una semana el pandillero ya no estaba ahí. Mayra y su familia debían buscar casa o rentar un cuarto, porque su estancia en el hotel había acabado. En un mes, pasaron por tres cuartos hasta que consiguió establecerse en un barrio en el sureste de Tapachula.

\section{La rabia de una madre migrante}

Un día de octubre, habíamos quedado en que iría a conocer su nueva casa. Noté que Mayra estaba animada por su tono de voz más fluido y activo. Minutos antes de partir, me llamó afligida que su pequeño hijo había sufrido un accidente. Ovidio se había roto el brazo. Era una operación compleja, el costo de los materiales era muy elevado y no estaban disponibles en el hospital de Tapachula. Así comenzó la búsqueda del dinero para solicitarlos y operar al niño.

Mayra tenía derecho al seguro popular por ser solicitante de refugio. Mientras ella cuidaba a su hijo, me entregó el papel que comprueba su derecho a la salud pública, y comencé a buscar atención para hacer efectivo el seguro. Dentro del hospital visité al menos tres ventanillas distintas, pero los resultados desde un principio fueron infructuosos. El seguro popular no cubría ningún gasto e incluso, los funcionarios sabían que el documento acreditaba el acceso a la salud de Mayra y su familia, no tendría ningún efecto para lograr costear la operación de su hijo. Todo terminó en una seguidilla de visitas a diferentes oficinas del hospital que se tradujeron en la acumulación de papeles, búsqueda de timbres y firmas que no resolvieron la urgencia de salud de Ovidio.

Intentamos conseguir financiamiento por medio de ACNUR, la OIM, la embajada de El Salvador y otro albergue que atiende a migrantes con problemas de salud y ninguna respondió ${ }^{20}$. Ovidio pasó cinco días en el hospital de

\footnotetext{
${ }^{20}$ En términos generales, gran parte de la producción de conocimiento sobre el tránsito migratorio de las mujeres centroamericanas por la frontera sur, está orientada a documentar las dificultades en el acceso a derechos sociales de las mujeres migrantes. Sin embargo, al parecer son escasas las investigaciones focalizadas en analizar el sistema
} 
Tapachula. Cuando el niño llevaba cuatro días en el hospital, agotada por no obtener ninguna respuesta satisfactoria sobre la operación de su hijo, Mayra salió del cuarto donde estaba su hijo en espera, y en el pasillo comenzó a gritar que por ser migrantes y pobres se olvidaron de Ovidio y estaban dilatando su operación. Los gritos de Mayra alertaron al enfermero que estaba a cargo de Ovidio, quien apareció en el pasillo e intentó calmarla. Mayra continuó reclamando en voz alta la demora en la atención de su hijo y su temor de que el niño enfermara de otra cosa dentro del hospital, el enfermero le pidió que bajara la voz por respeto a los otros pacientes que estaban alrededor. Ella accedió pero con sus gestos aún enfurecidos, se preocupó de que el funcionario entendiera que continuaba molesta. Finalmente, su pareja aceptó un préstamo de dinero que le ofreció su jefe y la pareja se endeudó para pagar los materiales de la operación.

Esta interacción, en la que Mayra esperaba respuestas concretas sobre la operación de su hijo en el hospital, deja entrever la sensación de injusticia a la que son orillados las y los migrantes en tránsito, quienes son permanentemente marginados de ejercer derechos sociales por su condición de transitoriedad. Siguiendo a Marina Ariza (2016, p. 283) "las emociones negativas pueden transmutar a otras emociones”. Así, vivir y aguantar las dinámicas de la injusticia tiene un límite.

Dado el contexto de precarización en Tapachula, atravesado por una fuerte corrupción que termina por desviar recursos económicos y con eso disminuir la inversión en servicios públicos, convive la imposibilidad de los migrantes en tránsito de ejercer derechos. Desde este enfoque, la rabia es una emoción prohibida para los migrantes, de quienes se espera una naturalización de la injusti$\mathrm{cia}^{21}$. Lo que vivenciamos en el hospital es un sistema de salud carcomido por

de salud público en Tapachula, aunque sí es posible aproximarse a otras producciones de conocimiento que retratan las intersecciones entre salud y enfermedad de las mujeres en movilidad en el estado de Chiapas. Así, Eugenia Bayona (2011) analiza los cruces entre pobreza, salud y enfermedad en mujeres rurales de la Sierra Chiapaneca abarcando la región de la frontera sur y enfatizando en el acceso limitado a los servicios de salud en esta región. Siguiendo a Bayona "los enfermos viajan de un lado a otro, son enviados de Motozintla a Huitxla, a Comitán o Tapachula, y, en casos muy urgentes, a la capital Tuxtla Gutiérrez. Los viajes y las esperas complican las atenciones de los enfermos y sus posibles curaciones. Las mujeres cuentan que en urgencias es frecuente encontrar un servicio asistencial transitorio, que receta pastillas para el dolor o suero para la debilidad, las intervenciones hospitalarias, como operaciones y cirugías más complicadas, se posponen o se trasladan a otros centros, y, de esta forma, se acumulan historias de personas mal atendidas, de muertes incluso provocadas por las incompetencias médicas" (BAYONA, 2011, p.103). De esta manera, el acceso limitado al derecho a la salud responde a una violencia estructural e institucional para las mujeres pobres y en movilidad en Chiapas.

${ }^{21}$ Esta escena etnografica ilustra cómo las emociones y subjetividades constituyen sistemas de jerarquización social. En específico, la rabia de Mayra encarna las prohibiciones y normas emocionales otorgadas a las mujeres migrantes. Esta propuesta analítica ha sido elaborada por otros investigadores, entre ellos, Federico Beserer (2000), quien rastrea lo que denomina como "sentimientos (in) apropiados" para las mujeres indígenas migrantes oaxaqueñas. Esto significa, iluminar las maneras en que la movilidad transnacional empuja a las mujeres indígenas de San 
la corrupción. Mayra decidió vincularse con el hospital general de Tapachula solo en la medida de lo necesario para gestionar la operación de Ovidio. El niño finalmente fue intervenido días después del accidente.

Las narrativas del miedo y la rabia son testimonios de un fenómeno complejo y multilateral que en la coyuntura de la frontera suroccidental expresa los costos sociales, subjetivos y emocionales de la migración forzada y las precarias condiciones que ofrece Tapachula para la acogida de migrantes y personas refugiadas. Pero estas narrativas también subrayan, que el encuentro con los repertorios emocionales negativos reaviva la capacidad de acción de las y los sujetos. En el transcurso del proyecto migratorio, las emociones negativas empujan a resolver nudos críticos de la vida cotidiana donde se hace evidente que el estado y la institucionalidad opera como un aparato burocrático que refuerza desigualdades estructurales.

\section{Tránsito migratorio, violencias y deseo no heterosexual}

María José desde los 16 años se desempeñó como trabajadora sexual para ayudar a su abuela quien padecía de diabetes. Estuvo presa de su libertad en dos ocasiones y aunque su biografía ha estado atravesada por la pobreza, habla de su incorporación al trabajo sexual con fluidez. En su narrativa parece no haber sufrimiento ni la vergüenza por ejercer como prostituta. Incluso todo lo contrario, deja claro que trabajar con su cuerpo y volcada al sexo como una forma de placer, era una actividad laboral que le agradaba. Comenzó en un bar de su localidad de origen, Santa Ana en El Salvador. Durante las primeras semanas en el bar, todavía ejercía el trabajo sexual como hombre homosexual después, cuenta, las relaciones cotidianas y de amistad con otras trabajadoras sexuales, la llevaron a transicionar a mujer. "María José: [Cuando era niña] vendía helados, de ahí empecé a vender café y a los 16 años me dediqué al trabajo sexual, yo de mi vida no me quejo pues.

\footnotetext{
Juan Mixtepec, Oaxaca a romper y/o desobedecer a los mandatos emocionales otorgados desde sus comunidades de origen. Según el autor, las experiencias emocionales de las mujeres migrantes rompen con los regímenes de sentimientos hegemónicos, encarnando sentimientos inapropiados. Besserer explica que los sentimientos inadecuados constituyen una forma de resistencia a la imposición del orden sentimental, "De ahí que use en las páginas que siguen la palabra (in) apropiado con el prefijo "in" entre paréntesis para referirme a los sentimientos apropiados por las mujeres que siendo considerados inadecuados en el contexto del régimen de sentimientos imperante, formaron parte del conjunto de cambio social y/o de la resistencia de las mujeres al orden imperante" (BESSERER, 2000, p.373).
} 
E: ¿̨cómo empezaste en el trabajo sexual?

María José: porque yo pasaba vendiendo por los bares y entonces como yo igual ya tenía mi preferencia sexual, entonces miraba yo que trabajaban ahí [en el bar] y todo. Como yo pasaba ahí [por el bar] le dije [al dueño del bar] que si tenía trabajo, y me dijo que de hacer la limpieza y todo eso, sí, me dijo.

E: ¿Cómo fue la primera vez que trabajaste como trabajadora sexual?

María José: Me gustó. Yo los primeros días ahí [en el bar], no empecé así de un solo vestido de mujer, pero de ahí seguí y como a las dos semanas me dio unas ropas una amiga y me dijo "-puchica María José, que te mirarías bonita”. Ya después con la curiosidad, y entonces le dije "ah bueno, está bueno", y me empecé a vestir y cuando me miré ya, hay unas fotos ya mi pelo lo tenía un poco largo, los saltos altos no los podía manejar, pero empecé con zapatos bajitos y así fui usando y bien...así me fui vistiendo y vistiendo hasta que me vestí de mujer. Prácticamente ya no me vestía de chero [chico], ya solo de chera [chica].

E: Y tu familia ¿sabía?

María José: Pues mi abuela, no se había dado cuenta, pero igual yo lo hacía porque tenía que ayudarle a mi abuela más que todo, porque mi abuela era diabética y a ella y a mi abuelo no alcanzaba para comprarle la medicina y le compraba la insulina y entonces yo se la compraba" (conversación con María José, 16 de noviembre de 2016).

En el ańo 2015, comenzó el hostigamiento de las maras barrio 18 y ese mismo año huyó a Escuintla, Guatemala. Allá vivió en casa de su hermano durante siete meses, después regresó a El Salvador y luego migró a Tapachula. María José pasó por varias reubicaciones hasta que pudo llegar a Nueva York, Estados Unidos donde reside hoy. El hecho que detonó su huida de Santa Ana, ocurrió en un bus cuando sintió que unos pandilleros la agarraron fuerte de su cabello y sin poder defenderse, se lo cortaron. Desde ese momento dejó de maquillarse, usar ropa colorida y tacos. "Me lo dejaron todo tijereteado, fue como un mes antes de salir de El Salvador, en diciembre del 2015. Ay, yo lloré infinitamente, me quería morir porque yo adoraba mi pelo. En un bus iba en la parte de atrás y cabal cuando sentí las tijeras" (Conversación con María José, noviembre de 2016$)^{22}$.

\footnotetext{
${ }^{22}$ Esta práctica tuvo la intención de territorializar el cuerpo de María José. La violencia organizada de las pandillas es reflejo de un modelo de masculinidad que busca imprimir a través de la violencia contra los cuerpos feminizados
} 
De esta manera, analizar la migración forzada en clave de género, es fundamental para comprender las subjetividades de las mujeres durante sus trayectorias migratorias. La desigualdad social, política y económica de los países del triángulo norte de Centroamérica y la violencia organizada de las maras en El Salvador ha empujado a la migración forzada de las diversidades sexuales. Cuando conocí a María José en el tránsito por Tapachula llevaba cabello corto con un jockey, no usaba ropa ajustada y tampoco se maquillaba. En las distintas fases de su movilidad, María José se movió entre atributos masculinos y femeninos para protegerse de las maras y la violencia contra su identidad de género. Esto demuestra que en la transitoriedad también circulan estrategias de autocuidado y conocimientos específicos que ayuda a las migrantes a moverse por Tapachula y sobrevivir a las fragilidades del tránsito.

Durante el trabajo de campo de esta propuesta, en Tapachula las mujeres migrantes trans y cisheterosexuales centroamericanas se encontraban regularmente en las plazas, los albergues, fuera de las instituciones, organizaciones de protección de derechos. Así, en medio de las amenazas siempre latentes de la violencia, las migrantes en tránsito logran configurar una "rutina” incluso en la incerteza del futuro, pero con una clara convicción de no quedarse. María José comenzó a trabajar como "chiclera" 23 , estrategia económica transitoria para las y los migrantes ante la dificultad de encontrar trabajo en Tapachula. En este escenario, comenzó el vínculo de amistad y deseo con Pedro -migrante, casado y con familia -quien le ayudó a pagar su caja para vender chicles y dulces en la calle. En el siguiente extracto, María José relata cómo en la transitoriedad, encontró en Pedro un compañero atento y preocupado.

"Con Pedro es bien diferente todo, todo, lo que he vivido con él. He encontrado algo bien diferente. Es alguien que no se aprovecha de ti, o sea, no sé pues, él es una persona tan buena onda que en veces yo no había vendido y él me decía “-monita, ¿vamos a tomar café?”, y yo reía, él me

\footnotetext{
y de las mujeres, mensajes de disputa de poder entre grupos de pares (VARELA HUERTA, 2017). Este cruce entre modelos hegemónicos de masculinidad y la violencia contra las mujeres es coherente en el marco de los mensajes que intercambian las fuerzas de orden y las maras en los países del triángulo norte de Centroamérica (El Salvador, Honduras y Guatemala). La persecución a la identidad trans de María José se explica por ser blanco favorable para el tráfico de drogas de las pandillas en el penal de Santa Ana. Su ingreso de drogas al penal, iría a fortalecer a la mara salvatrucha dentro de la cárcel, espacio de disputa de poder fundamental para las pandillas. Y dado que no cedió a estas presiones es que no tuvo otra salida más que huir.

${ }^{23}$ Término emic para referirse a los vendedores de chicle, dulces y cigarrillos sueltos. Cargan sobre sus hombros y cuello una caja de madera con compartimientos donde organizan los dulces. Esta venta asegura un ingreso mínimo e inmediato para subsistir al desempleo en la zona del Soconusco. Las cajas se consiguen en las dulcerías y su valor era entre 300 a 500 pesos mexicanos.
} 
invitaba. Cuando yo tenía “-¿vamos a comer?, vamos”. Íbamos a comer papas al mercado, yo compraba el aguacate, él compraba pa las tortillas, yo compraba queso y él compraba limones igual comíamos los dos, y a mi todo eso es lo que me hace falta, y puchica yo me vengo en depresión por ratitos. ¿Sabes cuánto vendí ayer? 10 pesos en todo el día, (conversación con María José, 1 de diciembre de 2016).

El trabajo de chiclero(a) es agotador y la ganancia de la venta es bastante relativa. Estas experiencias cotidianas del tránsito demuestran que las condiciones materiales influyen en la producción de subjetividades en contextos de movilidad. Aun cuando es necesario explorar las lógicas de desigualdad en la posición social de las y los migrantes, es importante tener en cuenta que sus emociones y afectos superan cualquier enfoque determinista sobre sus procesos de subjetivación. Así, María José encontró en Pedro la potencia afectiva necesaria para sobrevivir al tránsito migratorio de seis meses en Tapachula. Según María José, tendían a encontrarse más cuando estaban solos, esto ocurría sobre todo en las noches cuando vendían fuera de las cantinas.

Durante el día, en la medialuna del parque Miguel Hidalgo (uno de los principales puntos de reunión en Tapachula) solían reunirse varios migrantes cisheterosexuales y grupos migrantes LGBTI+, todos chicleros de origen salvadoreño u hondureño principalmente. Públicamente eran amigos, pero a solas eran amantes. A Pedro le preocupaba que su esposa y otros migrantes percibieran su vínculo cercano con María José. Pedro nunca reconoció abiertamente su deseo por María José. Esto refleja cómo el régimen heterosexual normativiza y reprime el deseo. Cuando estaban solos tenían encuentros erótico-afectivos, pero en el ámbito público y a la luz del día este deseo se tornaba una relación de amistad.

De esta manera, lo público y lo privado está en disputa cuando se trata de vínculos del deseo no heteronormativos. Durante el tránsito el uso de ciertos espacios en la ciudad producía regímenes de visibilidad e invisibilidad del deseo. Este constante devenir entre amistad y deseo en el vínculo de Pedro y María José, sólo es perceptible a la luz de una perspectiva crítica sobre las relaciones de género. Las normas emocionales están generizadas y operan con tal fuerza que los sujetos sean o no personas cisheterosexuales reproducen pautas y prácticas sobre estas normas, por ejemplo, en el imaginario del amor romántico.

Todo esto ocurre al mismo tiempo que la experiencia de María José, demuestra cómo el deseo de los cuerpos no heteronormativos tensiona las normas del placer heterosexual. Así, más allá de los binarismos que operan en las normas emocionales y que son nítidas en la demostración pública o privada del 
deseo, la relación entre Pedro y María José se convirtió en un espacio de reivindicación del placer, subjetividad prohibida para las y los migrantes en tránsito de quienes se espera únicamente sufrimiento.

\section{Reflexiones finales}

En este artículo se analizan las interacciones sociales que dan sentido a las experiencias del miedo, la rabia y el deseo no heterosexual de dos migrantes salvadoreńas en tránsito migratorio por Tapachula, ciudad fronteriza del sureste mexicano con Guatemala. Aunque su experiencia de transitoriedad está atravesada por dinámicas de desigualdad, -las cuales tienen como punto de partida sus lugares de origen, pero que se perpetúan durante el tránsito migratorio debido a la precarización del trabajo, la burocracia, y la discriminación en Tapachula-, este texto propone que en su travesía las emociones y afectos son potencias transformadoras para reelaborar continuamente sus proyectos migratorios. Se sostiene que incluso desde los repertorios emocionales negativos del miedo, la rabia y las múltiples incertezas del tránsito -todas experiencias relacionadas con las vulnerabilidades de la migración forzada-, nacieron espacios de agencia para afrontar su tránsito migratorio. En definitiva, en esta propuesta la situación vulnerabilidad no es equivalente a sumisión y tampoco responde a un movimiento unilateral del poder, sino que, desde el centro de estas precariedades emergen procesos de reelaboración de las subjetividades que permiten afrontarlas.

En la huida forzada de Mayra y María José desde sus lugares de origen en El Salvador y posterior reencuentro con los pandilleros en Tapachula, indica que el miedo es una emoción atravesada por las lógicas del género. Así, la amenaza de muerte se fija en la maternidad en el caso de Mayra, y en el cabello como símbolo del cuerpo feminizado de María José. De esta manera, la violencia organizada de las pandillas contra las mujeres no es aleatoria, en la propagación del miedo y la intimidación opera un orden de género que asegura la perpetuación de una disputa de poder entre pares.

El tránsito migratorio implica una constelación de subjetividades. Desde el punto de vista de las emociones, la espera por la resolución de su legal estancia en México, es un proceso tremendamente tenso y estresante para las mujeres migrantes. La transitoriedad es producida para que las personas en movilidad se mantengan estancadas en la inestabilidad del tránsito, además se espera que las y los viajeros normalicen las dinámicas de injusticia que aqueja sus vidas cotidianas. Así la experiencia de rabia en Mayra por la ineficiencia en el tratamiento de su hijo, demuestra que es una emoción prohibida para las personas en movilidad 
forzada. La producción discursiva del migrante como víctima, refuerza un imaginario que prohíbe algunas emociones y permite otras. Se espera que sean sumisos, callados y pasivos, que no se enfurezcan y que de ocurrir, no lo manifiesten. No obstante, en la rabia de Mayra la injusticia tiene un límite, es una fuerza que pone en jaque estas prohibiciones emocionales a los migrantes forzados.

Por su parte, en el vínculo entre María José y Pedro, el deseo es una experiencia corporal y subjetiva que se mueve a contracorriente de la producción discursiva del migrante como sujeto únicamente capaz de narrar o "tener una voz" desde el sufrimiento. El placer es una forma de agencia que -incluso desde los binarismos- les permite la reelaboración de sus condiciones de vulnerabilidad, le otorga reconocimiento a las corporalidades no heteronormativas y empuja a quienes interesan las movilidades, a avanzar hacia una visión mucho más compleja y menos determinista sobre las personas en movilidad.

Finalmente, las posibilidades para encontrar un trabajo en Tapachula son muy escasas, los sueldos son bajísimos y/o expone a las y los migrantes a situaciones de explotación laboral. Frente a este escenario, las redes de solidaridad son mucho más profundas que únicamente perseguir el cálculo racional de subsistencia del tránsito migratorio. De esta manera, estos vínculos transitorios entre la amistad y el deseo no sólo son estrategias de sobrevivencia animadas por las necesidades concretas que deben suplirse en el día a día, sino que también están fuertemente asentadas en emociones y afectos. El deseo de María José hacia Pedro es un vínculo afectivo que mucho más allá de resolver el problema la subsistencia económica, se configuró como un espacio de reconocimiento, placer, seguridad y contención durante la incertidumbre del tránsito migratorio.

\section{BIBLIOGRAFÍA}

AHMED, S. La política cultural de las emociones. Ciudad de México: Editorial Programa de Estudios de Género, 2015.

ÁNGELES, H. Las bandas maras salvatrucha en la región fronteriza del Soconusco, Chiapas. In: SANCHEZ VÁSQUEZ, E.; JARKIN, R. (org.). La frontera sur: Reflexiones sobre el Soconusco, Chiapas y sus problemas ambientales, poblacionales y productivos. Tapachula: Ecosur, COCYTECH-H, Ayuntamiento de Tapachula, 2004. p.143-156.

ARIZA, M. Tonalidades emocionales en la experiencia de la migración laboral: Humillación y degradación laboral In: ARIZA M. (org.). Emociones, Afectos y 
Sociología, Diálogos desde la investigación social y la interdisciplina. Ciudad de México: IIS-UNAM, 2016. p.279-325.

ASAKURA, H. Entramado de emociones: El malestar de la maternidad transnacional de las mujeres migrantes centroamericanas. In: RODRÍGUEZ, J. G.; MOCTEZUMA, M.; CALDERÓN, O. (org.). Hogares y familias transnacionales un encuentro desde la perspectiva humana. Ciudad de México: Juan Pablos Editor, Universidad de Sonora, Benemérita Universidad Autónoma de Puebla, 2016. p.137174.

ASAKURA, H.; FALCON, M. Entre dos fuegos: Naturalización e invisibilidad de la violencia de género contra migrantes en territorio mexicano. Ciudad de México: Publicaciones Casa Chata, 2019.

BAYONA, E. Enfermedad y pobreza en la Sierra de Chiapas. Revista LiminaR: Estudios sociales y humanísticos, San Cristóbal de Las Casas, v. IX, n. 2, 2011.

BESSERER, F. Sentimientos (in)apropiados de las mujeres migrantes: hacia una nueva ciudadanía. In: BARRERA, D.; OEHMICHEN C. (org.). Migración y relaciones de género en México. Ciudad de México: GIMTRAP-UNAM/IIA, 2000. p. 371-389.

BRAH, A. Cartografías de la diáspora: Identidades en cuestión. Madrid: Traficantes de sueños, 2011.

BUTLER, J. Marcos de guerra: Las vidas lloradas. Ciudad de México: Contextos Ideas, 2010.

CASTRO, Y. Etnografías de la movilidad y la contención de las migraciones: repensando los métodos de la antropología, Revista Antropologías del Sur, Santiago, v.6, n.11, p.17-37, 2019.

FÉRNANDEZ, C.; JUÁREZ, A. El punto más al sur y el punto más al norte: Tapachula y Tijuana como ciudades fronterizas escenarios de inmovilidades forzadas de migrantes, desplazados internos, solicitantes de refugio y deportados. Península, Ciudad de México, v. 14, n.2, p.155-174, 2019.

FERRANDIZ F.; FEIXA, C., Una mirada antropológica sobre las violencias. Alteridades, Ciudad de México, v.14, n. 27, p. 159-174, 2004.

GANDÁSEGUI, M. A.; PRECIADO, J. A. La sociología latinoamericana y las ciencias sociales: hegemonía, debate democrático y neoconservadurismo. In: GANDÁSEGUI, M.A.; PRECIADO, J. A. (org.). Hegemonía y democracia en disputa. Buenos Aires: CLACSO, 2017. p. 15-49. 
LAGARDE, M. Prefacio: claves feministas en torno al feminicidio. Construcción teórica, política y jurídica, In: FREGOSO, R. (org.). Feminicidio en América Latina. México: CEIICH: UNAM, 2011. p.11-41.

LÓPEZ, O. La pérdida del paraíso: el lugar de las emociones en la sociedad mexicana entre los siglos XIX y XX. Ciudad de México: Universidad Nacional Autónoma de México, 2011.

MAHMOOD, S. Teoria feminista, agência e sujeito libertório: algumas reflexóes sobre o revivalismo islâmico no Egito. Etnográfica, Lisboa, v.23, n.1, p. 135-175, 2019 .

MAURER, A. Trayectorias de cruces migración de mujeres trans* en Tijuana/ San Diego. 2019. Dissertação (Maestría en Antropología Social) - Universidad Iberoamericana, Ciudad de México, 2019. Orientador: Dr. Alejandro Agudo Sánchez.

MEZZADRA, S.; BRETT N. La frontera como método. Madrid: Traficantes de sueños, 2017.

MORAÑA, M. Postscríptum: El afecto en la caja de herramientas, In: MORAÑA, M.; SÁNCHEZ, M. I. (org.). El lenguaje de las emociones: Afecto y cultura en América Latina. Madrid: Iberoamericana-Vervuert, 2012. p.313-337.

ORTNER, S. B. Resistance and the problem of ethnographic refusal. Comparative Studies in Society and History, Cambridge, v. 37, n.1, p. 173-193, 1995.

PARRINI, R.; FLORES, E. El mapa son los otros: narrativas del viaje de migrantes centroamericanos en la frontera sur de México, Íconos: Revista de Ciencias Sociales, Quito, n.61, p. 71-90, 2018.

PEDWELL, C.; WHITEHEAD, A. Affecting Feminism: Questions of feeling in Feminist Theory, Feminist Theory, London, n. 2, p.115-129, 2012.

RAVELO, P. Cuerpos marcados por la violencia sexual. Niñas y mujeres jóvenes migrantes en la frontera norte. Sociológica, Mexico, año 32, n. 91, p. 317-332, 2017.

REGUILLO, R. La mara: contingencia y afiliación con el exceso. Nueva sociedad, Caracas, n.200, p.71-94, 2007.

ROJAS, M. Precariedades y vulnerabilidades en la migración: Notas para el análisis de la situación de mujeres centroamericanas en México. Astrolabio: Revista internacional de filosofía, Barcelona, n.18, p. 218-230, 2017.

ROSALDO, M. Toward an anthropology of self and feeling. In: SHWEDER, R. A.; LEVINE, R. A. Culture Theory: essays on mind, self and emotion. Cambrigde: Cambrigde University Press, 1984. p. 138-157. 
SCHEPER-HUGHES, N.; BOURGOIS, P. Violence in war in peace: an anthology. Oxford: Blackwell Publishing, 2004.

VARELA HUERTA, A. La trinidad perversa de la que huyen las fugitivas centroamericanas: violencia feminicida, violencia de estado y violencia de mercado, Debate Feminista, Ciudad de Mexico, n. 53, p. 1-17, 2017.

WINTON, A. Entre fronteras: Un estudio exploratario sobre diversidad sexual y movilidad en la Frontera Sur de México. Tapachula, México: Una Mano Amiga: Ecosur: ACNUR, 2016. Disponible en: https://www.academia.edu/27211444/ Entre_Fronteras_Un_estudio_exploratorio_sobre_diversidad_sexual_y_movilidad_ en_la_Frontera_Sur_de_M\%C3\%A9xico. Acceso en: 01 ago. 2021.

Recebido em: 31 de agosto de 2020

Aprovado em: 14 de dezembro de 2020 